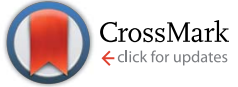

Cite this: RSC Adv., 2017, 7, 1016

Received 3rd November 2016

Accepted 18th November 2016

DOI: $10.1039 / \mathrm{c} 6 \mathrm{ra} 26245 \mathrm{~g}$

www.rsc.org/advances

\section{Synthesis of di(ethylene glycol)-functionalized diketopyrrolopyrrole derivative-based side chain- conjugated polymers for bulk heterojunction solar cellsł}

\begin{abstract}
Rong-Ho Lee, ${ }^{\text {aa }}$ Lun-Cheng Yang, ${ }^{a}$ Jeng-Yue $\mathrm{Wu}^{\mathrm{a}}$ and Ru-Jong Jeng ${ }^{\mathrm{b}}$
Polythiophenes (PTs) featuring di(ethylene glycol)-substituted 2,5-thienyl diketopyrrolopyrrole (DG-TDPP) moieties as conjugated units in the polymer backbone and tert-butyl-substituted triphenylamine ( $t$ TPA)containing moieties as pendant units have been synthesized through Stille coupling. Incorporating the electron-deficient DG-TDPP moieties within the polymer backbone and appending the tTPA units promoted charge balance and efficient conjugation within the extended conjugated frameworks of the polymers, resulting in lower band gap energies and red-shifting the maximum UV-Vis absorption wavelength. The influence of the DG-TDPP content on the optical, electrochemical, and photovoltaic (PV) properties of the polymers has been studied. Incorporating a suitable content of DG-TDPP moieties in the polymer backbone enhanced the solar absorption ability and conjugation length of the PTs. The PV properties of bulk-heterojunction solar cells based on PT/fullerene derivatives improved after incorporating DG-TDPP units in the backbones of the side chain-conjugated PTs.
\end{abstract}

\section{Introduction}

Optoelectronic devices fabricated from conjugated polymers have attracted much attention recently because they can be processed simply and inexpensively over large areas with flexible shapes and light weight. ${ }^{1-3}$ In the case of polymer solar cells (PSCs), major advances in solar energy conversion efficiencies have been accomplished by replacing the double-layer cell with a bulk-heterojunction (BHJ) blend for the photoactive layer. ${ }^{4-6}$ For most BHJ cells, the photoactive layer is based on a blend of an electron-donor polymer and an electron-acceptor fullerene derivative, either [6,6]-phenyl- $\mathrm{C}_{61}$-butyric acid methyl ester $\left(\mathrm{PC}_{61} \mathrm{BM}\right)$ or $[6,6]$-phenyl- $\mathrm{C}_{71}$-butyric acid methyl ester $\left(\mathrm{PC}_{71} \mathrm{BM}\right) .^{7}$ An electron-donor polymer having a low band gap is crucial when attempting to harvest large amounts of solar radiation. Using this approach, PSCs have been obtained with high short-circuit current densities $\left(J_{\mathrm{SC}}\right){ }^{\mathbf{8}, \mathbf{9}}$ Moreover, high charge mobility is also required of the polymer in PSCs to minimize charge recombination in the photoactive layer, and to achieve high degrees of charge collection and large values of $J_{\mathrm{SC}} \cdot{ }^{10}$ In addition, the energy level of the lowest unoccupied

${ }^{a}$ Department of Chemical Engineering, National Chung Hsing University, Taichung 402, Taiwan. E-mail: rhl@dragon.nchu.edu.tw; Fax:+886-4-22854734; Tel: +886-422854308

${ }^{b}$ Institute of Polymer Science and Engineering, National Taiwan University, Taipei 106, Taiwan

$\uparrow$ Electronic supplementary information (ESI) available. See DOI: $10.1039 /$ c6ra26245g molecular orbital (LUMO) of the polymer must be appropriately offset from that of the electron-acceptor fullerene derivative. ${ }^{11} \mathrm{~A}$ polymer having a deep highest occupied molecular orbital (HOMO) energy level favors a PSC having a large open-circuit voltage $\left(V_{\mathrm{OC}}\right) \cdot{ }^{\mathbf{1 2 , 1 3}}$ On the other hand, a phase-separated interpenetrating network featuring sizable fullerene derivative-based domains in the photoactive layer facilitates the efficient formation of free carriers, thereby providing PSCs displaying optimal photovoltaic (PV) properties. ${ }^{14-16}$

PSCs providing good PV performance have been studied widely in which the conjugated polymers contain p-type electron-donating groups and electron-donating and -withdrawing donor-acceptor (D-A)-type structures. ${ }^{\mathbf{1 0 , 1 2 , 1 7}}$ The bipolar characteristics of conjugated polymers containing electron- and hole-transporting moieties are responsible for the lower-energy band gaps and higher charge mobilities of the photoactive layers that can enhance the PV efficiencies of PSCs. In addition, polythiophene (PT) derivatives bearing electron-donating and -withdrawing pendant groups, so-called two-dimensional low band gap conjugated polymers, have been proposed by several groups for PSC applications. ${ }^{18-26}$ PT derivatives bearing conjugated pendant units absorb broadly in the UV and visible regions and can, therefore, harvest greater amounts of solar light. Moreover, the pendant conjugated moieties can enhance the charge mobilities of the polymers. Recently, we synthesized a series of PTs presenting pendant conjugated triphenylamine (TPA)- or carbazole-containing moieties as side chains. ${ }^{27}$ Although the TPA- or carbazole-based conjugated pendant 
moieties enhanced the conjugation of the PTs, the cutoff wavelength of the absorption of these p-type conjugated polymers remained less than $750 \mathrm{~nm}$. In addition, electron-deficient moieties, including benzothiadiazole and 2,5-thienyl diketopyrrolopyrrole (TDPP) units, have been incorporated into the backbones of polymers presenting electron-donating conjugated pendant units. ${ }^{28-32}$ The presence of TDPP units in the polymer backbone enhanced the absorption edge to wavelengths of up to $1000 \mathrm{~nm} \cdot{ }^{33-35}$ Unfortunately, increasing the TDPP content decreased the solubility of the polymers, due to increased degrees of $\pi-\pi$ stacking among the polymer chains. The power conversion efficiencies (PCEs) of such polymer-based PSCs are not high. ${ }^{33,34}$ Therefore, precise control over the molar ratio of electron-donating and -withdrawing units in a polymer chain is necessary to optimize the solubility and the optical and PV performance of their devices.

To validate these ideas, we synthesized a series of PTs (PEGA11, PEGA12, PEGA13) featuring di(ethylene glycol)substituted 2,5-thienyl diketopyrrolopyrrole (DG-TDPP) moieties as conjugated units in the polymer backbones and tertbutyl-substituted triphenylamine ( $t$ TPA)-containing moieties as pendant units. We expected the conjugated DG-TDPP units with di(ethylene glycol) segments as flexible chains would improve the solubility of the PTs. We used UV-Vis absorption spectroscopy and cyclic voltammetry (CV) to study the effect of the DGTDPP content on the photophysical and electrochemical properties of the polymers. We also employed atomic force microscopy (AFM) and transmission electron microscopy (TEM) to study the morphologies of thin films prepared from $\mathrm{PT} / \mathrm{PC}_{61} \mathrm{BM}$ blends. We then fabricated PSCs having the conventional structure indium tin oxide (ITO)-coated glass/hole-transporting medium (HTM)/photoactive layer/LiF $(0.5 \mathrm{~nm}) / \mathrm{Al}(100 \mathrm{~nm})$, by spin-coating a blend of each PT with $\mathrm{PC}_{61} \mathrm{BM}$ (or $\mathrm{PC}_{71} \mathrm{BM}$ ) to form a composite film-type photoactive layer on the HTM layer deposited on the ITO-coated glass. Based on the evaluated PV performance of these PSCs, we determined the influence of the DG-TDPP content of our PTs.

\section{Experimental details}

\subsection{Chemicals}

Potassium carbonate $\left(\mathrm{K}_{2} \mathrm{CO}_{3}\right) \mathrm{N}$-bromosuccinimide (NBS), tris(dibenzylideneacetone)dipalladium $(0) \quad\left[\mathrm{Pd}_{2}(\mathrm{dba})_{3}\right], \quad \operatorname{tri}(o-$ tolyl)phosphine $\left[\mathrm{P}(o \text {-tolyl })_{3}\right], 2$-(2-ethoxyethoxy)ethyl bromide, and other reagents and chemicals were purchased from Aldrich, Alfa, Acros, and TCI Chemical, and used as received. Chloroform $\left(\mathrm{CHCl}_{3}\right)$, dimethylformamide (DMF), toluene, and $o$ dichlorobenzene $(o$-DCB) were freshly distilled over appropriate drying agents, then purged with $\mathrm{N}_{2}$, prior to use. 3,6-Di(thien-2yl)-2,5-dihydropyrrolo[3,4-c]pyrrole-1,4-dione (1), 2,5-bis(trimethylstannyl)thiophene (4), and (E)-4-(5-(2-(2,5-dibromothiophen-3-yl)vinyl)thien-2-yl)- $N, N$-((4,40-di-tert-butyl)diphenyl) aniline (5) were synthesized according to the literature..$^{27,35,36}$ The syntheses of 3,6-di(thien-2-yl)-2,5-di(2-(2-ethoxyethoxy) ethyl)-pyrrolo[3,4-c]pyrrole-1,4-dione (2) and 3,6-di(5-bromothien-2-yl)-2,5-di(2-(2-ethoxyethoxy)ethyl)pyrrolo[3,4-c]pyrrole1,4-dione (3) are illustrated in Scheme 1. The syntheses of PTs
(PEGA11, PEGA12, and PEGA13) featuring DG-TDPP moieties as conjugated units in the polymer backbones and $t$ TPAcontaining moieties as side chains are also illustrated in Scheme 1.

\subsection{Synthesis}

3,6-Di(thien-2-yl)-2,5-di(2-(2-ethoxyethoxy)ethyl)pyrrolo[3,4c]pyrrole-1,4-dione (2). A solution of compound $1(2.50 \mathrm{~g}, 8.33$ $\mathrm{mmol}), \mathrm{K}_{2} \mathrm{CO}_{3}(3.83 \mathrm{~g}, 27.80 \mathrm{mmol})$, and [18]-crown-6 (0.250 g, $0.95 \mathrm{mmol})$ in dry DMF $(50 \mathrm{~mL})$ was stirred at $120{ }^{\circ} \mathrm{C}$ under $\mathrm{N}_{2}$ for $10 \mathrm{~min}$ and then a solution of 2-(2-ethoxyethoxy)ethyl bromide $(4.17 \mathrm{~mL}, 27.5 \mathrm{mmol})$ in dry DMF $(30 \mathrm{~mL})$ was added dropwise. The resulting solution was heated with stirring for $20 \mathrm{~h}$. After cooling to room temperature, the mixture was partitioned between $\mathrm{CH}_{2} \mathrm{Cl}_{2}$ and water; the organic phase was dried $\left(\mathrm{MgSO}_{4}\right)$, filtered, and evaporated to dryness. The residue was purified chromatographically $\left(\mathrm{SiO}_{2} ; \mathrm{EtOAc} /\right.$ hexane, $\left.1: 4\right)$ to provide a dark-red solid $(1.82 \mathrm{~g}, 41.9 \%) .{ }^{1} \mathrm{H}$ NMR $(\delta / \mathrm{ppm}, 600$ $\left.\mathrm{MHz}, \mathrm{CDCl}_{3}\right): 1.15(\mathrm{t}, 6 \mathrm{H}), 3.44(\mathrm{q}, 4 \mathrm{H}), 3.52(\mathrm{t}, 4 \mathrm{H}), 3.62(\mathrm{t}, 4 \mathrm{H})$, $3.79(\mathrm{t}, 4 \mathrm{H}), 4.27(\mathrm{t}, 4 \mathrm{H}), 7.25(\mathrm{t}, 2 \mathrm{H}), 7.63(\mathrm{~d}, 2 \mathrm{H}), 8.73(\mathrm{~d}, 2 \mathrm{H})$. Anal. calcd for $\mathrm{C}_{26} \mathrm{H}_{32} \mathrm{~N}_{2} \mathrm{O}_{6} \mathrm{~S}_{2}$ : C, 58.67; H, 6.02; N, 5.26; O, 18.05; S, 12.0. Found: C, 58.65; H, 6.07; N, 5.24; O, 18.04; S, 11.97.

3,6-Di(5-bromothien-2-yl)-2,5-di(2-(2-ethoxyethoxy)ethyl)pyrrolo[3,4-c]pyrrole-1,4-dione (3). A solution of $4(0.53 \mathrm{~g}, 1.0$ $\mathrm{mmol})$ in $\mathrm{CHCl}_{3}(30 \mathrm{~mL})$ was stirred at room temperature for $10 \mathrm{~min}$ and then a solution of NBS $(0.45 \mathrm{~g}, 2.3 \mathrm{mmol})$ in $\mathrm{CHCl}_{3}$ (30 $\mathrm{mL})$ was added dropwise. The resulting solution was stirred at room temperature for $12 \mathrm{~h}$. The mixture was then partitioned between $\mathrm{CH}_{2} \mathrm{Cl}_{2}$ and water; the organic phase was dried $\left(\mathrm{MgSO}_{4}\right)$, filtered, and evaporated to dryness. The residue was recrystallized in $\mathrm{MeOH}$ to provide a purple solid $(0.29 \mathrm{~g}, 42.0 \%)$. ${ }^{1} \mathrm{H}$ NMR $\left(\delta / \mathrm{ppm}, 600 \mathrm{MHz}, \mathrm{CDCl}_{3}\right): 1.16(\mathrm{t}, 6 \mathrm{H}), 3.45(\mathrm{q}, 4 \mathrm{H})$, $3.51(\mathrm{t}, 4 \mathrm{H}), 3.62(\mathrm{t}, 4 \mathrm{H}), 3.78(\mathrm{t}, 4 \mathrm{H}), 4.17(\mathrm{t}, 4 \mathrm{H}), 7.20(\mathrm{~d}, 2 \mathrm{H})$, 8.48 (d, 2H). Anal. calcd for $\mathrm{C}_{26} \mathrm{H}_{30} \mathrm{~N}_{2} \mathrm{O}_{6} \mathrm{~S}_{2} \mathrm{Br}_{2}$ : C, 45.22; $\mathrm{H}, 4.35$; $\mathrm{N}, 4.06$; O, 13.91; S, 9.28. Found: C, 45.28; H, 4.31; N, 4.03; O, 13.86; S, 9.31 .

PEGA11. A solution of $5(0.35 \mathrm{~g}, 0.50 \mathrm{mmol}), 6(0.41 \mathrm{~g}, 1.0$ $\mathrm{mmol})$, and $7(0.35 \mathrm{~g}, 0.50 \mathrm{mmol})$ in dry toluene $(30 \mathrm{~mL})$ was stirred at room temperature under $\mathrm{N}_{2}$ for $10 \mathrm{~min}$ and then a solution of $\mathrm{Pd}_{2}(\mathrm{dba})_{3}(36.6 \mathrm{mg}, 0.04 \mathrm{mmol})$ and $\mathrm{P}(o \text {-tolyl })_{3}$ $(48.7 \mathrm{mg}, 0.16 \mathrm{mmol})$ in dry toluene $(10 \mathrm{~mL})$ was added dropwise. The resulting solution was heated with stirring at $90{ }^{\circ} \mathrm{C}$ for $48 \mathrm{~h}$. After cooling to room temperature, the solution was poured into $\mathrm{MeOH}(100 \mathrm{~mL})$. The precipitate was filtered off, placed in a Soxhlet thimble, and extracted sequentially with $\mathrm{MeOH}$, hexane, acetone, $\mathrm{CHCl}_{3}$, and $o$-DCB. The polymer PEGA11 was recovered from the $o$-DCB fraction through rotary evaporation. Drying under vacuum for $24 \mathrm{~h}$ provided a black solid (0.24 g, 21.4\%). ${ }^{1} \mathrm{H}$ NMR ( $\left.\delta / \mathrm{ppm}, 600 \mathrm{MHz}, \mathrm{CD}_{2} \mathrm{Cl}_{2}\right): 0.75-$ $1.39(\mathrm{~m}, 28 \mathrm{H}), 3.15-3.71(\mathrm{~m}, 20 \mathrm{H}), 6.35-7.62$ (m, 28H). Anal. calcd for $\left[\left(\mathrm{C}_{26} \mathrm{H}_{30} \mathrm{~N}_{2} \mathrm{O}_{6} \mathrm{~S}_{2}\right)\left(\mathrm{C}_{40} \mathrm{H}_{37} \mathrm{NS}_{3}\right)_{1.25}\right]$ : C, 69.42; H, 5.80; N, 3.46; O, 7.31; S, 14.01. Found: C, 69.55; H, 5.75; N, 3.53; O, 7.37; S, 13.80 .

PEGA12. Using the procedure described above for the synthesis of PEGA11, the reaction of $5(0.23 \mathrm{~g}, 0.33 \mathrm{mmol}), 6$ (0.41 g, $1.0 \mathrm{mmol})$, and 7 (0.47 g, $0.67 \mathrm{mmol})$ provided PEGA12 


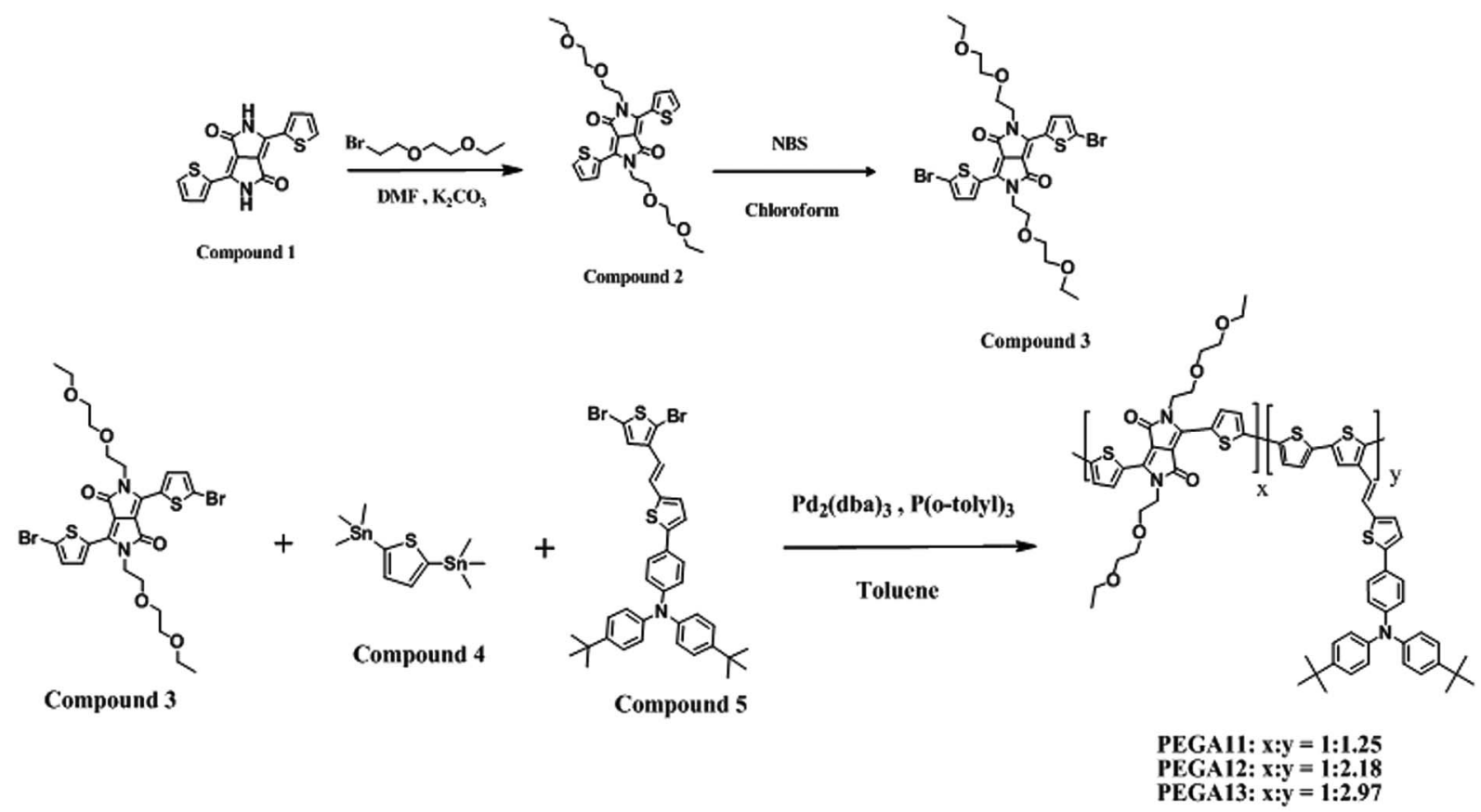

Scheme 1 Synthesis of compounds 2, 3, PEGA11, PEGA12, and PEGA13.

as a black solid $(0.16 \mathrm{~g}, 14.4 \%) .{ }^{1} \mathrm{H}$ NMR $(\delta / \mathrm{ppm}, 600 \mathrm{MHz}$, $\mathrm{CD}_{2} \mathrm{Cl}_{2}$ ): 0.75-1.40 (m, 45H), 3.10-3.75 (m, 20H), 6.30-7.60 (m, $46 \mathrm{H})$. Anal. calcd for $\left[\left(\mathrm{C}_{26} \mathrm{H}_{30} \mathrm{~N}_{2} \mathrm{O}_{6} \mathrm{~S}_{2}\right)\left(\mathrm{C}_{40} \mathrm{H}_{37} \mathrm{NS}_{3}\right)_{2.18}\right]$ : C, 71.61; H, 5.83; N, 3.09; O, 5.06; S, 14.41. Found: C, 71.59; H, 5.89; N, 3.05; O, 5.10; S, 14.37 .

PEGA13. Using the procedure described above for the synthesis of PEGA11, the reaction of $5(0.17 \mathrm{~g}, 0.25 \mathrm{mmol}), 6$ (0.41 g, $1.0 \mathrm{mmol})$, and 7 ( $0.53 \mathrm{~g}, 0.75 \mathrm{mmol})$ provided PEGA13 as a black solid $(0.26 \mathrm{~g}, 23.4 \%) .{ }^{1} \mathrm{H} \mathrm{NMR}(\delta / \mathrm{ppm}, 600 \mathrm{MHz}$, $\mathrm{CD}_{2} \mathrm{Cl}_{2}$ ): 0.65-1.40 (m, 60H), 3.05-3.75 (m, 20H), 6.30-7.42 (m, $60 \mathrm{H})$. Anal. calcd for $\left[\left(\mathrm{C}_{26} \mathrm{H}_{30} \mathrm{~N}_{2} \mathrm{O}_{6} \mathrm{~S}_{2}\right)\left(\mathrm{C}_{40} \mathrm{H}_{37} \mathrm{NS}_{3}\right)_{2.97}\right]$ : C, 72.64; $\mathrm{H}, 5.85$; N, 2.90; O, 4.01; S, 14.64. Found: C, 72.60; H, 5.91; N, 2.88; O, 4.10; S, 14.51 .

\subsection{Characterization of copolymers}

${ }^{1} \mathrm{H}$ NMR (600 MHz) spectra were recorded using a Varian Unity Inova spectrometer. The average molecular weights of the polymers were measured by means of gel permeation chromatography (GPC), using a Waters chromatography system (717 plus Autosampler) equipped with two Waters Styragel linear columns, employing polystyrene (PS) standards and THF as the eluent. The glass transition temperatures $\left(T_{\mathrm{g}}\right)$ and thermal decomposition temperatures $\left(T_{\mathrm{d}}\right.$; temperatures at which weight loss reached $5 \%$ ) of the copolymers were determined through differential scanning calorimetry (TA Instruments, DSC-2010) and thermogravimetric analysis (TA Instruments, TGA-2050), respectively. Both analyses were performed under a $\mathrm{N}_{2}$ atmosphere at scanning (both heating and cooling) rates of $10^{\circ} \mathrm{C}$ $\min ^{-1}$. The temperatures at the intercepts of the curves in the thermograms (endothermic, exothermic, or weight loss) with the leading baseline were taken as estimates of the values of $T_{\mathrm{g}}$ and $T_{\mathrm{d}}$. Absorption spectra were recorded using a Hitachi U3010
UV-Vis spectrometer; dilute $o$-DCB solutions of the PTs were filtered through a $0.45 \mu \mathrm{m}$ filter to remove insoluble materials prior to spectral measurement. The redox potentials of the polymers were determined using a CHI 611D electrochemical analyzer (scanning rate: $50 \mathrm{mV} \mathrm{s}^{-1}$ ) equipped with Pt electrodes and an $\mathrm{Ag} / \mathrm{Ag}^{+}$(0.10 $\mathrm{M} \mathrm{AgNO}_{3}$ in $\left.\mathrm{MeCN}\right)$ reference electrode in an anhydrous, $\mathrm{N}_{2}$-saturated solution of $0.1 \mathrm{M} \mathrm{Bu}_{4} \mathrm{NClO}_{4}$ in MeCN. $\mathrm{Bu}_{4} \mathrm{NClO}_{4}(98 \%$, TCI) was recrystallized three times from $\mathrm{MeOH}$ and water $(1: 1)$ and then dried at $100{ }^{\circ} \mathrm{C}$ under reduced pressure. A Pt plate coated with a thin polymer film was used as the working electrode; a Pt wire and an $\mathrm{Ag} / \mathrm{Ag}^{+}$electrode were used as the counter and reference electrodes, respectively. The electrochemical potential was calibrated against ferrocene/ ferrocenium. The morphologies of films prepared from PT/ $\mathrm{PC}_{61} \mathrm{BM}$ blends were studied using an atomic force microscope (AFM, Seiko SII SPA400) operated in the tapping mode and a transmission electron microscope (TEM, JEOL JEM-1400).

\subsection{Fabrication and characterization of PSCs}

The PSCs fabricated in this study had the structure ITO-coated glass/HTM/photoactive layer/LiF $(0.5 \mathrm{~nm}) / \mathrm{Al}(100 \mathrm{~nm})$, where the photoactive layer comprised an interpenetrating network of a PT and a fullerene derivative ( $\mathrm{PC}_{61} \mathrm{BM}$ or $\left.\mathrm{PC}_{71} \mathrm{BM}\right)$. ITO-coated glass (sheet resistance: $20 \Omega$ per square) was purchased from Applied Film Corp. $\mathrm{PC}_{61} \mathrm{BM}$ and $\mathrm{PC}_{71} \mathrm{BM}$ were purchased from Nanocarbon Corp. and used as received. The PSCs were fabricated as follows: glass substrates with patterned ITO electrodes were washed well and then cleaned through $\mathrm{O}_{2}$ plasma treatment. A thin film of the HTM, poly(3,4-ethylenedioxythiophene) doped with poly(styrene sulfonate) (PEDOT:PSS, AI4083, Heraeus Clevios $\mathrm{GmbH}$ ), was deposited on the ITO layer through spin-casting. The sample was dried at $150{ }^{\circ} \mathrm{C}$ for $30 \mathrm{~min}$ in 
a glove box. A solution of a mixture of $\mathrm{PT}$ and $\mathrm{PC}_{61} \mathrm{BM}$ (or $\left.\mathrm{PC}_{71} \mathrm{BM}\right)\left(30 \mathrm{mg} \mathrm{mL}^{-1}\right.$ in $o$-DCB) was stirred overnight, then filtered through a $0.2 \mu \mathrm{m}$ polytetrafluoroethylene (PTFE) filter and spin-coated (1500 rpm, $30 \mathrm{~s}$ ) onto the HTM layer to prepare the $\mathrm{PT} / \mathrm{PC}_{61} \mathrm{BM}$ (or $\mathrm{PC}_{71} \mathrm{BM}$ ) composite film-based photoactive layer. The sample was dried at $110^{\circ} \mathrm{C}$ for $10 \mathrm{~min}$ in a glove box. In a high-vacuum chamber, the $\mathrm{Ca} / \mathrm{Al}$-based cathode was thermally deposited onto the $\mathrm{PT} / \mathrm{PC}_{61} \mathrm{BM}$ (or $\mathrm{PC}_{71} \mathrm{BM}$ ) composite layer. The active area of the PSC was $0.04 \mathrm{~cm}^{2}$. After electrode deposition, the PSC was encapsulated. The cathode deposition rate was determined using a quartz thickness monitor (STM100/MF, Sycon). The thicknesses of the thin films were determined using a surface texture analysis system (3030ST, Dektak). The PV properties of the PSCs were measured using a programmable electrometer equipped with current and voltage sources (Keithley 2400) under illumination with solar-

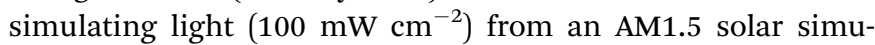
lator (NewPort Oriel 96000).

\section{Results and discussion}

\subsection{Characterization of PTs}

The conjugated PTs were synthesized through Stille coupling of DG-TDPP (3), 2,5-bis(trimethylstannyl)thiophene (4), and $t$ TPAcontaining thiophene derivative (5). The chemical structures of the monomers were confirmed using ${ }^{1} \mathrm{H}$ NMR spectroscopy and elemental analysis. ${ }^{1} \mathrm{H}$ NMR spectra of compounds 3-5 and PTs are shown in Fig. S1 and S2, $\uparrow$ respectively. Chemical shifts and relative intensities of the signals in the ${ }^{1} \mathrm{H}$ NMR spectra were in agreement with the proposed structures of compounds 3-5 and PTs. The repeat unit ratios $(x / y$; see Scheme 1$)$ of the PTs (PEGA11, PEGA12, and PEGA13) were modulated by controlling the feed ratio of the DG-TDPP and conjugated pendant $t$ TPAcontaining thiophene derivative 5. For the copolymers PEGA11, PEGA12, and PEGA13, the actual values of $x / y$ were determined from the relative integral areas of their peaks at 6.20-7.60 ppm (representing protons of the vinylene, phenyl, and thiophene groups) and 3.10-3.80 [representing protons of di(ethylene glycol) groups] in the ${ }^{1} \mathrm{H}$ NMR spectra. The values of $x / y$ of PEGA11, PEGA12, and PEGA13 were approximately $1: 1.25,1: 2.18$, and $1: 2.97$, respectively. Using GPC with THF as the eluent and PS internal standards, we determined the number-average molecular weights $\left(M_{\mathrm{n}}\right)$ and weight-average molecular weights $\left(M_{\mathrm{w}}\right)$ of the conjugated PTs. As summarized in Table 1, the values of $M_{\mathrm{n}}$ and $M_{\mathrm{w}}$ of the conjugated polymers were in the ranges $6.5-13.5$ and $14.5-28.4 \mathrm{~kg} \mathrm{~mol}^{-1}$, respectively. The average molecular weights of PEGA11 and PEGA12

Table 1 Average molecular weights and thermal properties of the PTs

\begin{tabular}{lclll}
\hline PT & $M_{\mathrm{n}}\left(\mathrm{kg} \mathrm{mol}^{-1}\right)$ & $M_{\mathrm{w}}\left(\mathrm{kg} \mathrm{mol}^{-1}\right)$ & $T_{\mathrm{g}}{ }^{a}\left({ }^{\circ} \mathrm{C}\right)$ & $T_{\mathrm{d}}{ }^{b}\left({ }^{\circ} \mathrm{C}\right)$ \\
\hline PEGA11 & 6.5 & 14.5 & 113.4 & 319.8 \\
PEGA12 & 7.8 & 16.4 & 112.8 & 347.1 \\
PEGA13 & 13.5 & 28.4 & 120.9 & 398.5
\end{tabular}

${ }^{a} T_{\mathrm{g}}$ : measured at a heating rate of $10{ }^{\circ} \mathrm{C} \min ^{-1} \cdot{ }^{b} T_{\mathrm{d}}$ : temperature at which weight loss reached $5 \%$. were much lower than that of PEGA13. The early termination of the propagation of the polymer chains resulted from poor solubility of the polymers in the reaction solution and, accordingly, their precipitation. As a result, we observed relatively lower average molecular weights for PEGA11 and PEGA12. Relatively poorer solubility of PEGA11 and PEGA12 was due to their higher contents of DG-TDDP units. In fact, relatively poorer solubility of PT with higher DG-TDDP contents was attributed to the strong intermolecular hydrogen-bonding interactions between the lactam units. ${ }^{37}$ Nevertheless, these three conjugated copolymers were all soluble in common organic solvents, including THF, $\mathrm{CH}_{2} \mathrm{Cl}_{2}, \mathrm{CHCl}_{3}$, and $o$-DCB. Excellent solubility is favorable for the formation of the solution-processed PTs based photo-active layers.

The operational stability of a PSCs is directly related to the thermal stability of its component conjugated polymer. Thus, high values of $T_{\mathrm{g}}$ and $T_{\mathrm{d}}$ are desirable. We measured the values of $T_{\mathrm{g}}$ and $T_{\mathrm{d}}$ of our conjugated copolymers by means of thermal analyses using DSC and TGA (Table 1). The values of $T_{\mathrm{d}}$ for PEGA13, PEGA12, and PEGA11 were 398.5, 347.1, and $319.8^{\circ} \mathrm{C}$, respectively. The thermal stability of the PTs decreased upon increasing the DG-TDPP content. Moreover, we determined glass transition temperatures from the second round of DSC
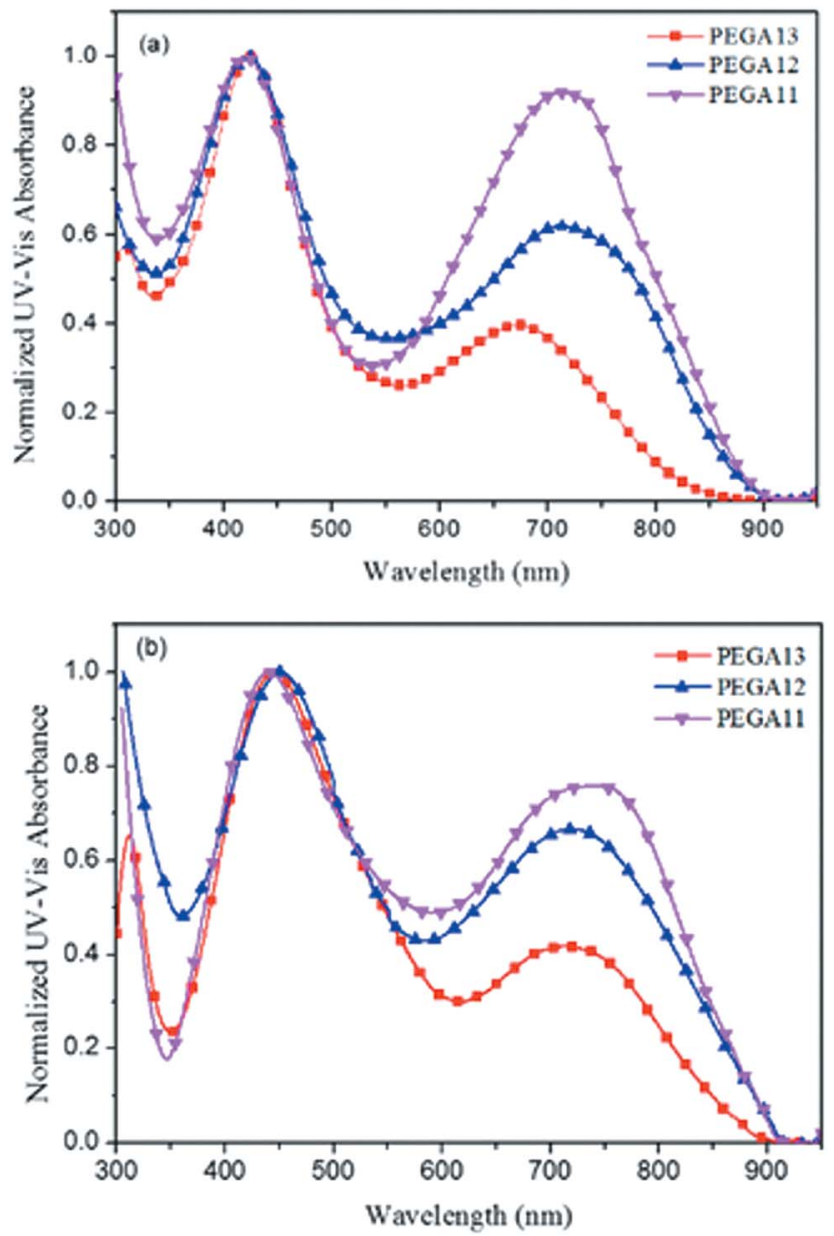

Fig. 1 Normalized UV-Vis absorption spectra of PTS (a) in o-DCB solution and (b) as thin films. 
Table 2 Optical properties, electrochemical onset potentials, and electronic energy levels of the PTs

\begin{tabular}{|c|c|c|c|c|c|c|}
\hline $\mathrm{PT}$ & $\lambda_{\max }^{\mathrm{abs} a}(\mathrm{~nm})$ & $\lambda_{\max }^{\mathrm{abs} b}(\mathrm{~nm})$ & $E_{\mathrm{g}}^{\mathrm{optc}}(\mathrm{eV})$ & $E_{\mathrm{on}}^{\mathrm{ox}}(\mathrm{V})$ & HOMO (eV) & LUMO $(\mathrm{eV})$ \\
\hline PEGA11 & 420,717 & 445,740 & 1.40 & 0.40 & -5.11 & -3.71 \\
\hline PEGA12 & 423,715 & 450,722 & 1.41 & 0.38 & -5.09 & -3.68 \\
\hline
\end{tabular}

${ }^{a}$ Maximum absorption wavelength of polymer in solution. ${ }^{b}$ Maximum absorption wavelength of polymer as thin film. ${ }^{c}$ Calculated value of $E_{\mathrm{g}}$ from the onset absorption ( $\lambda_{\text {onset }}^{\text {abs }}$ ) of polymer thin film: $E_{\mathrm{g}}=1240 / \lambda_{\text {onset }}$.
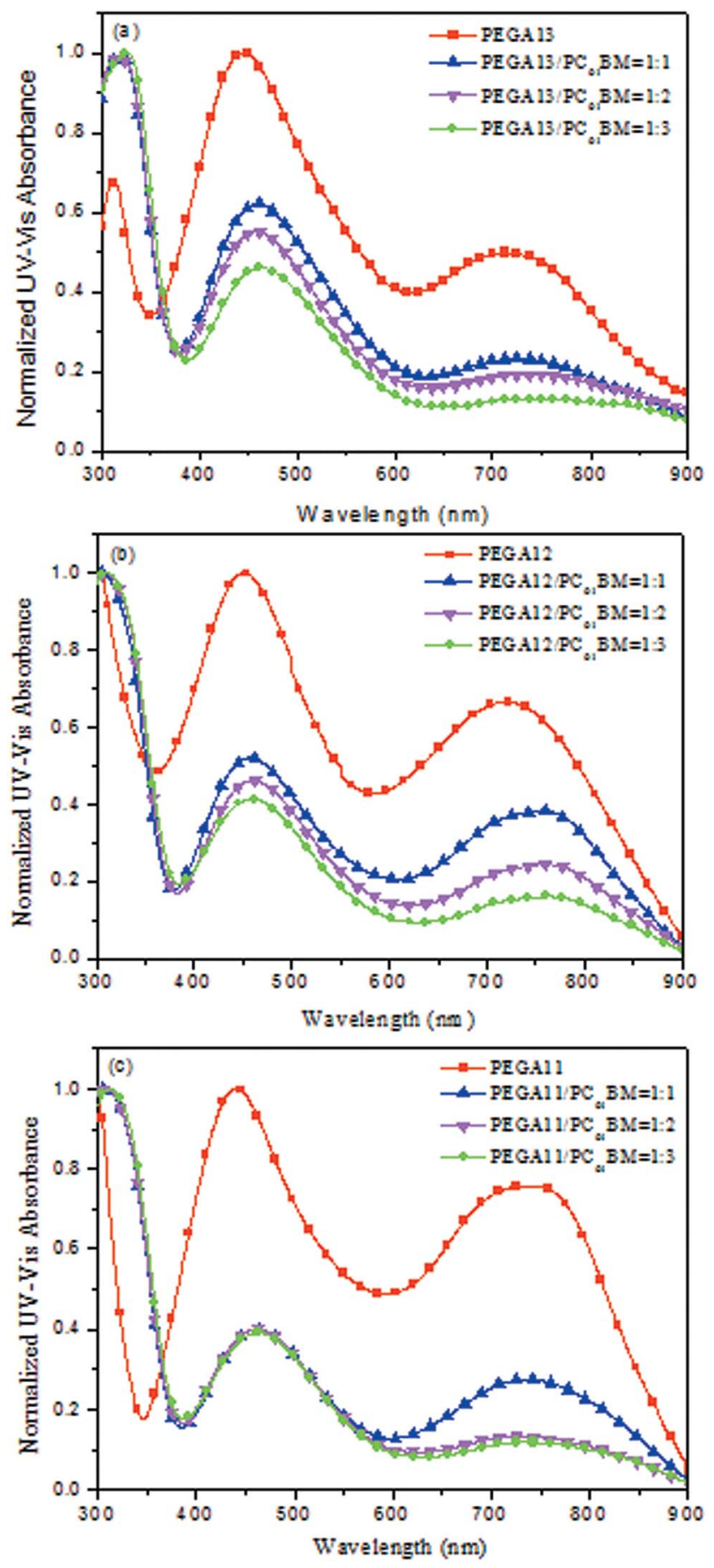

Fig. 2 Normalized UV-Vis absorption spectra of (a) PEGA13/PC ${ }_{61} B M$, (b) PEGA12/PC ${ }_{61} \mathrm{BM}$, and (c) PEGA11/PC ${ }_{61} \mathrm{BM}$ blend films. heating scans. The values of $T_{\mathrm{g}}$ for PEGA13, PEGA12, and PEGA11 were $120.9,112.8$, and $113.4{ }^{\circ} \mathrm{C}$, respectively, making them suitable for PSC applications. Relatively low values of $T_{\mathrm{g}}$ resulted from the polymers having higher contents of flexible di(ethylene glycol)-substituted diketopyrrolopyrrole units. In addition, we observed a single endothermic glass transition for each conjugated copolymer, implying that the diketopyrrolopyrrole conjugated units and electron-donating bulky $t$ TPAcontaining pendant moieties were distributed homogeneously.

\subsection{Optical properties of PTs}

Fig. 1 presents normalized UV-Vis absorption spectra of the DG-TDPP-containing PTs as solutions in $o$-DCB and as solid films. Table 2 summarizes their photophysical properties. The absorptions of the DG-TDPP-containing PTs in $o$-DCB ranged from 325 to $900 \mathrm{~nm}$; each polymer displayed two broad absorption bands. We attribute the first absorption band, in the range $350-550 \mathrm{~nm}$, to the $\mathrm{n}-\pi^{*}$ transitions of the conjugated side chains and the $\pi-\pi^{*}$ transitions of the conjugated main chains. The second absorption band, in the range 550-900 nm, originated from intramolecular charge transfer (ICT) between the thiophene-based donor units and DG-TDPP-based acceptor units. $^{33,34}$ The absorption intensities of the second absorption band increased upon increasing the content of DG-TDPP units in the copolymers, both in solution and as thin films. Moreover, the red-shifts and full widths at half-maximum of the absorption bands of the copolymers in their film forms were greater

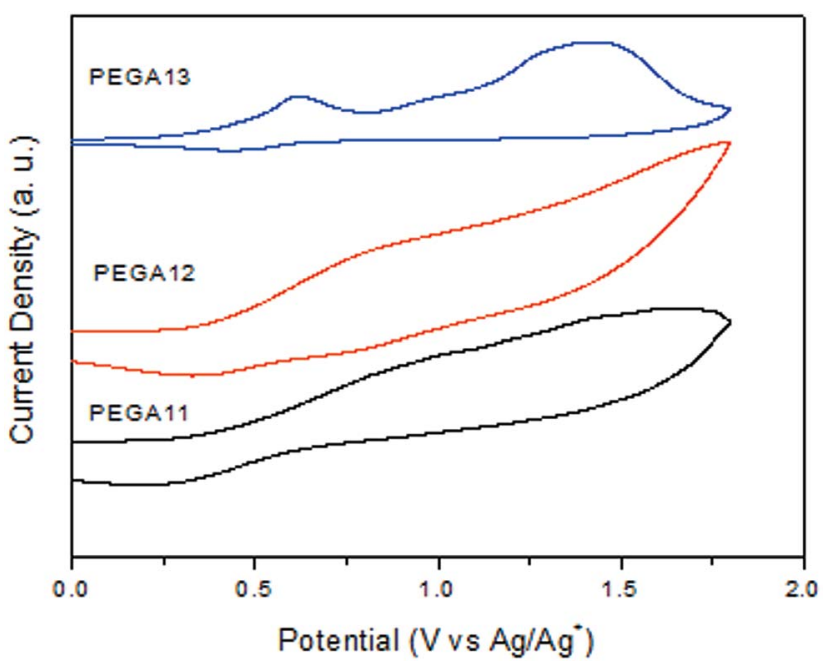

Fig. 3 Cyclic voltammograms of PEGA11, PEGA12, and PEGA13. 
than those in solution, presumably because of strong noncovalent interactions (e.g., $\pi$-stacking) between the polymer backbones and conjugated pendant units. ${ }^{27,36}$

We determined the band gap energies $\left(E_{\mathrm{g}}\right)$ of the conjugated polymers in their thin film states from the onset wavelengths of their absorption bands. Table 2 reveals that the values of $E_{\mathrm{g}}$ for PEGA11, PEGA12, and PEGA13 were 1.40, 1.41, and $1.47 \mathrm{eV}$, respectively. The lower values of $E_{\mathrm{g}}$ were observed for the copolymers having higher contents of DG-TDPP units. In general, a broader absorption range and a lower band gap energy will improve the efficiency of solar light absorption of the photo-energy conversion layer in a PSC, resulting in the generation of a larger photocurrent.

Fig. 2 displays normalized UV-Vis absorption spectra of the $\mathrm{PT} / \mathrm{PC}_{61} \mathrm{BM}$ composite films. The absorption bands of the DGTDPP-containing copolymers ranged from 375 to $900 \mathrm{~nm}$,
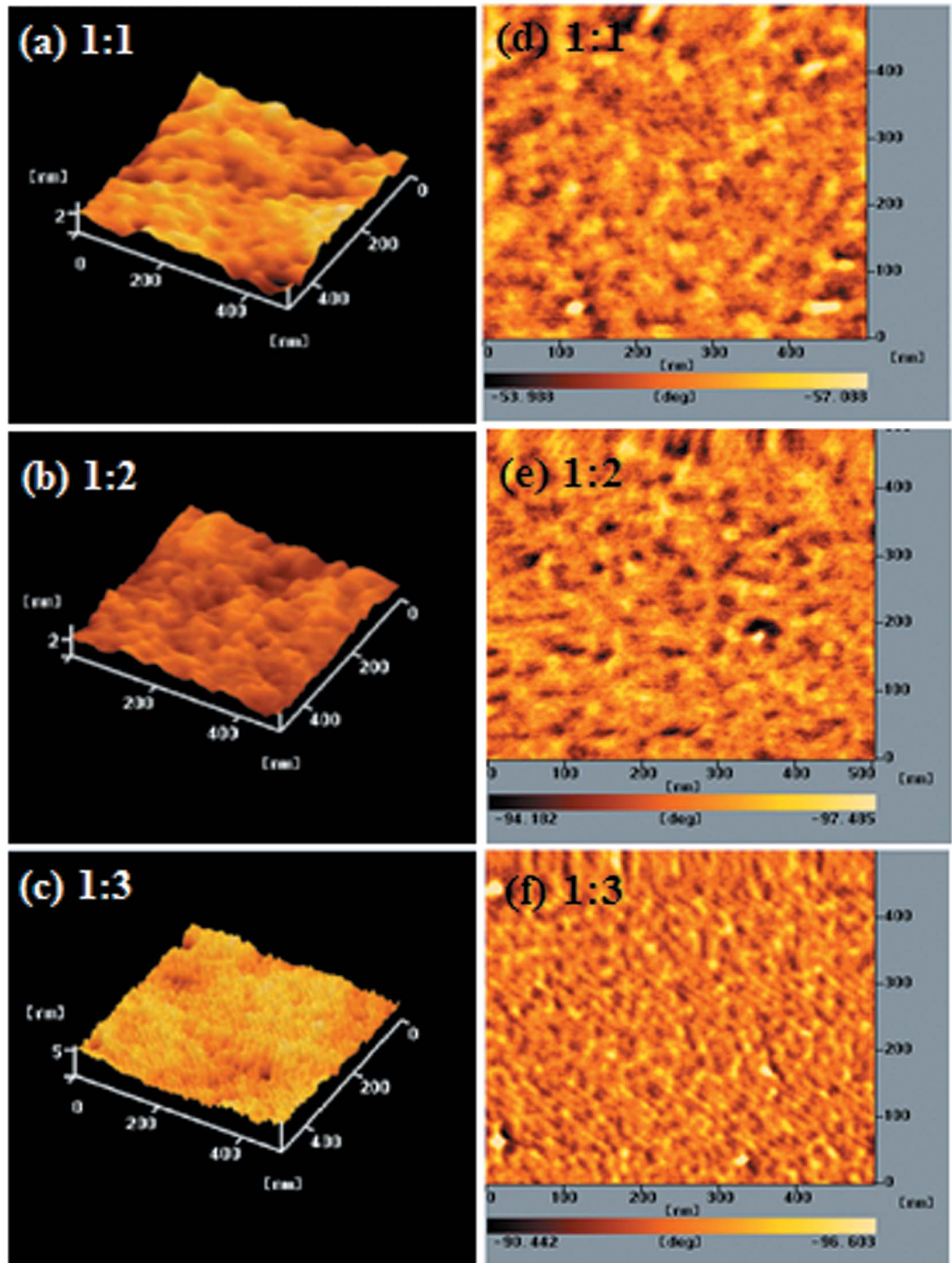

Fig. 4 AFM (tapping mode) $(a-c)$ topographic and $(d-f)$ phase images of PEGA13/PC ${ }_{61} B M$ blend films [(a and d) $1: 1, w / w ;(b$ and e) $1: 2$, w/w; (c and f) $1: 3, \mathrm{w} / \mathrm{w}$ ] after annealing at $110^{\circ} \mathrm{C}$ for $10 \mathrm{~min}$. 
while the absorption band of $\mathrm{PC}_{61} \mathrm{BM}$ ranges from 300 to $375 \mathrm{~nm}$. The maximum absorption peaks of the conjugated copolymer and $\mathrm{PC}_{61} \mathrm{BM}$ appeared near 425 and $325 \mathrm{~nm}$, respectively. Moreover, the absorption intensity of the conjugated polymer decreased as the $\mathrm{PC}_{61} \mathrm{BM}$ content increased for these $\mathrm{PT} / \mathrm{PC}_{61} \mathrm{BM}$ composite films. From the viewpoint of photon absorption, employing less $\mathrm{PC}_{61} \mathrm{BM}$ in the photoactive layer would be preferred. Nevertheless, the typical stoichiometry of polymer/PC ${ }_{61} \mathrm{BM}$ blends, optimal for devices in several PSC systems, ranges from $1: 1$ to $1: 4$ by weight. ${ }^{38} \mathrm{~A}$ high proportion of $\mathrm{PC}_{61} \mathrm{BM}$ limits the optical absorption in the composite layer because the absorption of $\mathrm{PC}_{61} \mathrm{BM}$ is quite inefficient in the visible region.

\subsection{Electrochemical properties of PTs}

Because the PV performance of a PSC is related to the electrochemical behavior of its conjugated polymer, we employed $\mathrm{CV}$ to investigate the electrochemical behavior of our PTs and estimate the energy levels of their HOMOs. Fig. 3 presents the oxidation behavior in the CV curves of the PTs. Table 2 summarizes the electrochemical properties of the copolymers. The oxidation potentials ( $E_{\text {on }}^{\text {ox }}$ ) of PEGA11, PEGA12, and PEGA13 were $0.40,0.38$, and $0.26 \mathrm{~V}$, respectively. From those values, we calculated the HOMO energy levels of the copolymers according to the equation

$$
\mathrm{HOMO}=-e\left(E_{\mathrm{on}}^{\mathrm{ox}}-E_{\mathrm{on}}^{\mathrm{ox}}, \text { ferrocene }+4.71\right)(\mathrm{eV})
$$

where $4.71 \mathrm{eV}$ is the energy level of ferrocene below the vacuum level and the value of $E_{\text {on }}^{\mathrm{ox}}$ of ferrocene/ferrocene ${ }^{+}$is $0.09 \mathrm{~V}$ in $0.1 \mathrm{M} \mathrm{Bu}_{4} \mathrm{NClO}_{4} / \mathrm{MeCN}$. The HOMO energy levels obtained for PEGA11, PEGA12, and PEGA13 were -5.11, -5.09, and $-4.97 \mathrm{eV}$, respectively. Lower HOMO energy levels were observed for the PTs having lower contents of $t$ TPA-containing conjugated pendant units, suggesting lower electron-donating abilities for these polymers. ${ }^{39}$ In addition, because no

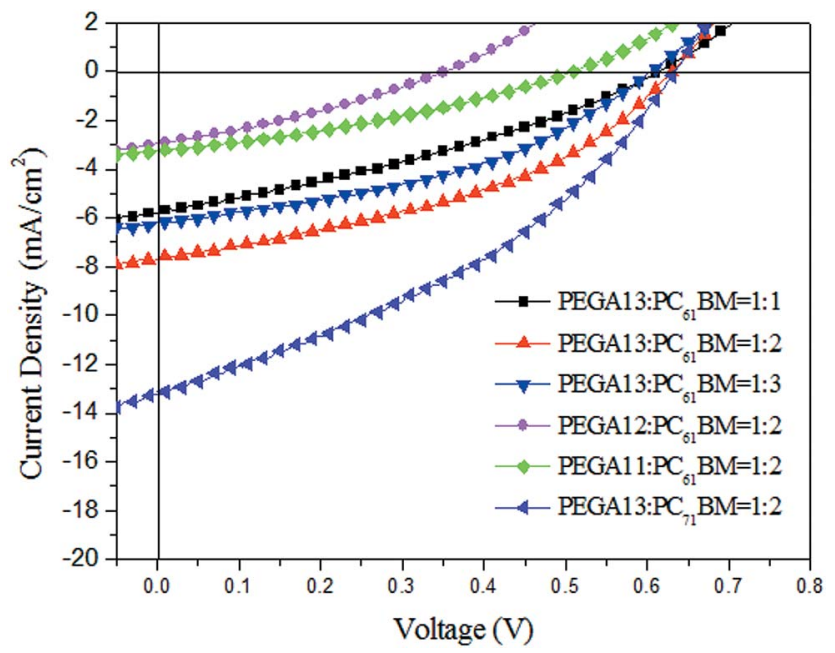

Fig. 5 Current density-potential characteristics of illuminated (AM $1.5 \mathrm{G}, 100 \mathrm{~mW} \mathrm{~cm}^{-2}$ ) PSCs incorporating (PEGA13, PEGA12, PEGA11)/ $\mathrm{PC}_{61} \mathrm{BM}$ and $\mathrm{PEGA} 13 / \mathrm{PC}_{71} \mathrm{BM}$ blends. reversible n-doping process was evident in the CV spectra, we estimated the LUMO energy levels from the HOMO energy levels and the values of $E_{\mathrm{g}}$ determined from the UV-Vis absorption spectra, using the equation

$$
\mathrm{LUMO}=\mathrm{HOMO}+E_{\mathrm{g}}(\mathrm{eV})
$$

The calculated LUMO energy levels were $-3.71 \mathrm{eV}$ for PEGA11, $-3.68 \mathrm{eV}$ for PEGA12, and -3.50 eV for PEGA13. Lower LUMO levels were obtained for the PTs having higher contents of electron-deficient (i.e., DG-TDPP) units. Thus, the electrochemical properties of these PTs could be tuned by incorporating electron-accepting DG-TDPP units into the polymer backbone. In general, the HOMO energy level of a p-type conjugated polymer is an important parameter affecting the performance of BHJ-type cells. High open-circuit voltages $\left(V_{\mathrm{OC}}\right)$ are typically obtained for PSCs fabricated from conjugated polymers having low HOMO energy levels. ${ }^{12}$

\subsection{Morphology of thin films of $\mathrm{PT} / \mathrm{PC}_{61} \mathrm{BM}$ blends}

The performance of a PSC is strongly dependent on the morphology of the film of its conjugated polymer/fullerene derivative composite. To avoid recombination of excitons, the $\mathrm{P} / \mathrm{N}$ heterojunction phase must be controlled at the nanoscale level. ${ }^{27,36}$ We used AFM microscopy to investigate the compatibility and morphology of our conjugated polymer $/ \mathrm{PC}_{61} \mathrm{BM}$ composite films. Fig. 4 displays topographic and phase-contrast images of PEGA13/PC ${ }_{61} \mathrm{BM}$ composite films $(1: 1,1: 2$, and $1: 3, \mathrm{w} / \mathrm{w}$ ) after annealing at $110{ }^{\circ} \mathrm{C}$ for $10 \mathrm{~min}$; Fig. S3 and S4 (ESI $\dagger$ ) present the corresponding the topographic and phasecontrast images of the PEGA11/PC ${ }_{61} \mathrm{BM}$ and PEGA12/ $\mathrm{PC}_{61} \mathrm{BM}$ composite films $(1: 1,1: 2$, and $1: 3, \mathrm{w} / \mathrm{w})$. The phase-contrast images indicated that the distribution of the $\mathrm{PC}_{61} \mathrm{BM}$ units in the polymers was uniform for the DG-TDPP-containing PT/ $\mathrm{PC}_{61} \mathrm{BM}$ composite films. In each case, we observed a phaseseparated interpenetrating network with sizable $\mathrm{PC}_{61} \mathrm{BM}$ domains. Some degree of phase separation is critical for efficient formation of free carriers to provide PSCs with optimal PV properties. Moreover, the sizes of the phase separation domains decreased upon increasing the $\mathrm{PC}_{61} \mathrm{BM}$ content. The nanoscale phase separation was more obvious for the $\mathrm{PT} / \mathrm{PC}_{61} \mathrm{BM}$ composite film having the higher $\mathrm{PC}_{61} \mathrm{BM}$ content $(1: 3, \mathrm{w} / \mathrm{w})$. Larger interface area will be obtained for $\mathrm{PT} / \mathrm{PC}_{61} \mathrm{BM}$ composite films having larger $\mathrm{PC}_{61} \mathrm{BM}$ contents and smaller domain sizes.

\subsection{PV properties of PSCs incorporating $\mathrm{PT} / \mathrm{PC}_{61} \mathrm{BM}$ films}

We used an optimized spin-coating procedure to fabricate PSCs incorporating $\mathrm{PT} / \mathrm{PC}_{61} \mathrm{BM}$ blends as photoactive layers. Fig. 5 displays the photocurrent density-voltage plots of these PSCs; Table 3 summarizes the PV properties of these PSCs, including their values of $V_{\mathrm{OC}}, J_{\mathrm{SC}}$, fill factor (FF), and photoconversion efficiency $(\eta)$. For the PEGA13/PC ${ }_{61}$ BM-based PSCs (PSC I-1-PSC I-3), the value of $V_{\mathrm{OC}}$ did not change significantly in response to the content of $\mathrm{PC}_{61} \mathrm{BM}$. Moreover, the values of $J_{\mathrm{SC}}, \mathrm{FF}$, and $\eta$ of the PSCs increased upon increasing the $\mathrm{PC}_{61} \mathrm{BM}$ content. The 
Table 3 Photovoltaic performance of PSCs incorporating films of (PEGA13, PEGA12, PEGA11)/PC ${ }_{61} \mathrm{BM}_{\text {and }} \mathrm{PEGA13}_{\mathrm{PC}} \mathrm{B}_{71} \mathrm{BM}_{\text {blends }}$

\begin{tabular}{|c|c|c|c|c|c|c|c|}
\hline PSC & Photoactive layer & $\begin{array}{l}\mathrm{PT} / \mathrm{PC}_{61} \mathrm{BM} \\
\left(\text { or } \mathrm{PC}_{71} \mathrm{BM}\right)(\mathrm{w} / \mathrm{w})\end{array}$ & $V_{\text {OC }}(\mathrm{V})$ & $J_{\mathrm{SC}}\left(\mathrm{mA} \mathrm{cm}{ }^{-2}\right)$ & FF & $\eta(\%)$ & $\begin{array}{l}\text { Mobility } \\
\left(10^{-5} \mathrm{~cm}^{2} \mathrm{~V}^{-1} \mathrm{~s}^{-1}\right)\end{array}$ \\
\hline PSC I-1 & PEGA13/PC ${ }_{61} \mathrm{BM}$ & $1: 1$ & 0.61 & 5.8 & 0.32 & 1.1 & 1.79 \\
\hline PSC I-2 & PEGA13/PC ${ }_{61} \mathrm{BM}$ & $1: 2$ & 0.63 & 7.7 & 0.41 & 2.0 & 2.04 \\
\hline PSC I-3 & PEGA13/PC ${ }_{61} \mathrm{BM}$ & $1: 3$ & 0.60 & 6.7 & 0.40 & 1.6 & 1.86 \\
\hline PSC II & PEGA12/PC ${ }_{61} \mathrm{BM}$ & $1: 2$ & 0.35 & 2.9 & 0.32 & 0.3 & 1.54 \\
\hline PSC III & PEGA11/PC ${ }_{61} \mathrm{BM}$ & $1: 2$ & 0.51 & 3.2 & 0.33 & 0.5 & 1.36 \\
\hline PSC IV & PEGA13/PC ${ }_{71} \mathrm{BM}$ & $1: 2$ & 0.67 & 9.0 & 0.42 & 2.5 & 3.17 \\
\hline
\end{tabular}

highest values of $J_{\mathrm{SC}}$ and $\eta$ were observed for the PSC based on a photoactive layer of PEGA13/PC ${ }_{61} \mathrm{BM}$ at a weight ratio of $1: 2$. Higher concentrations of $\mathrm{PC}_{61} \mathrm{BM}$ in the photoactive layer favored the formation of phase-separated interpenetrating networks with sizable domains, which in turn led to effective charge separation and charge transfer. ${ }^{27}$ Typically, efficient dissociation of excitons and higher degrees of charge collection to the electrode are favorable for PSCs displaying enhanced

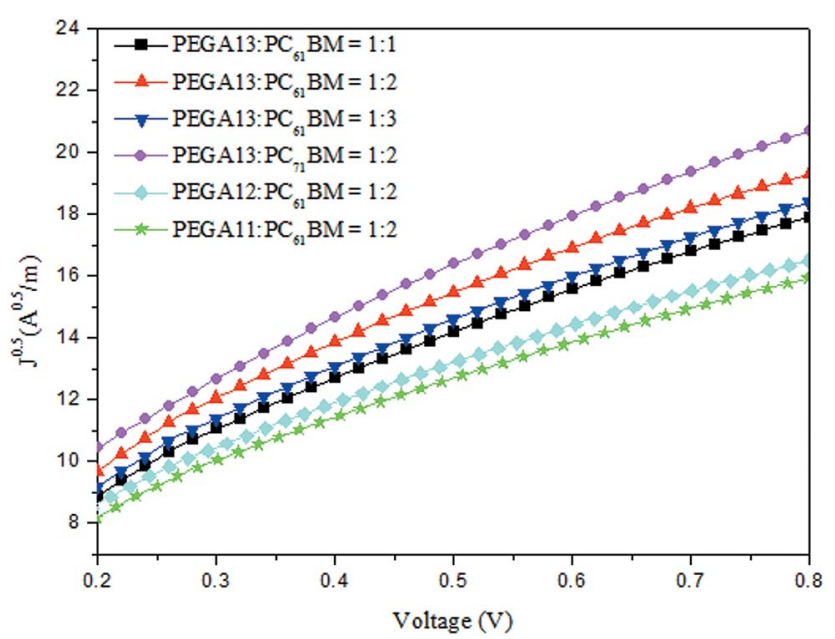

Fig. 6 Plots of $(J)^{0.5}$ Vs. $V$ of hole-only devices incorporating PT/ $\mathrm{PC}_{61} \mathrm{BM}$ and $\mathrm{PEGA} 13 / \mathrm{PC}_{71} \mathrm{BM}$ blends. values of $J_{\mathrm{SC}}$. Nevertheless, an excessive content of $\mathrm{PC}_{61} \mathrm{BM}$ does not favor the charge transfer behavior and PV performance of PSCs. The PV performance of PSC I-3 was poorer than that of PSC I-2. This finding implies that the optimal PT-to- $\mathrm{PC}_{61} \mathrm{BM}$ composition was approximately $1: 2(\mathrm{w} / \mathrm{w})$ for the PEGA13based PSCs. In addition, the hole mobility of a photoactive layer also plays an important role affecting the PV performance of a PSC. We used the space-charge limited current method to measure the hole mobilities of our $\mathrm{PT} / \mathrm{PC}_{61} \mathrm{BM}$ blend films, with a typical hole-only device structure of ITO/PEODT/PT:PC ${ }_{61} \mathrm{BM}$ (or $\mathrm{PC}_{71} \mathrm{BM}$ ) $/ \mathrm{Au}^{40}$ Fig. 6 presents the results plotted as the current density $(J)$ with respect to voltage $(V)$. Table 3 summarizes the hole mobilities of the blend films. The hole mobility of the $1: 2(\mathrm{w} / \mathrm{w})$ PEGA13/PC ${ }_{61} \mathrm{BM}$ blend film $\left(2.04 \times 10^{-5} \mathrm{~cm}^{2} \mathrm{~V}^{-1}\right.$ $\left.\mathrm{s}^{-1}\right)$ was greater than those of the corresponding $1: 1(1.79 \times$ $\left.10^{-5} \mathrm{~cm}^{2} \mathrm{~V}^{-1} \mathrm{~s}^{-1}\right)$ and $1: 3\left(1.86 \times 10^{-5} \mathrm{~cm}^{2} \mathrm{~V}^{-1} \mathrm{~s}^{-1}\right)$ blend films. The relatively higher hole mobility of the PEGA13/ $\mathrm{PC}_{61} \mathrm{BM}$ $(1: 2, \mathrm{w} / \mathrm{w})$ blend film resulted in the better PV performance of PSC I-2. On the other hand, the PV properties of the PEGA11and PEGA12-based PSCs (PSC II and PSC III, respectively) were much poorer than those of the PEGA13-based PSCs, reflecting the lower average molecular weights and poorer hole mobilities of PEGA11 and PEGA12. The hole mobilities of PEGA11/PC ${ }_{61} \mathrm{BM}$ and PEGA12/PC ${ }_{61} \mathrm{BM}$ were lower than that of PEGA13/ $\mathrm{PC}_{61} \mathrm{BM}$ (Table 3).

To further improve the PV performance of the PEGA13-based PSCs, we introduced $\mathrm{PC}_{71} \mathrm{BM}$ as the electron-acceptor in the
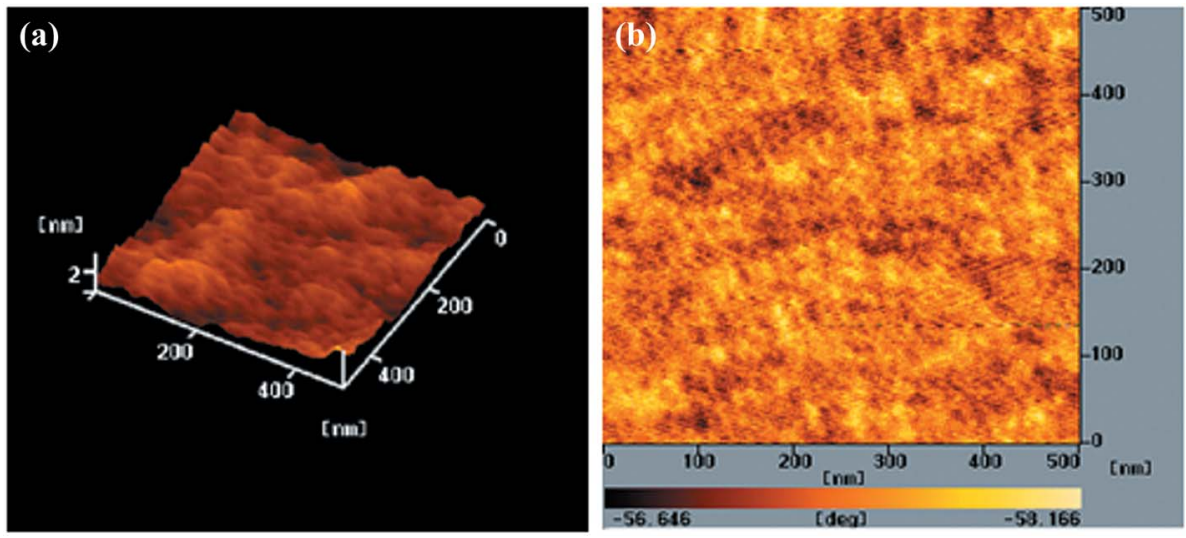

Fig. 7 AFM (tapping mode) (a) topographic and (b) phase images of the PEGA13/PC ${ }_{71} \mathrm{BM}(1: 2, \mathrm{w} / \mathrm{w})$ blend film after annealing at $110{ }^{\circ} \mathrm{C}$ for 10 min. 


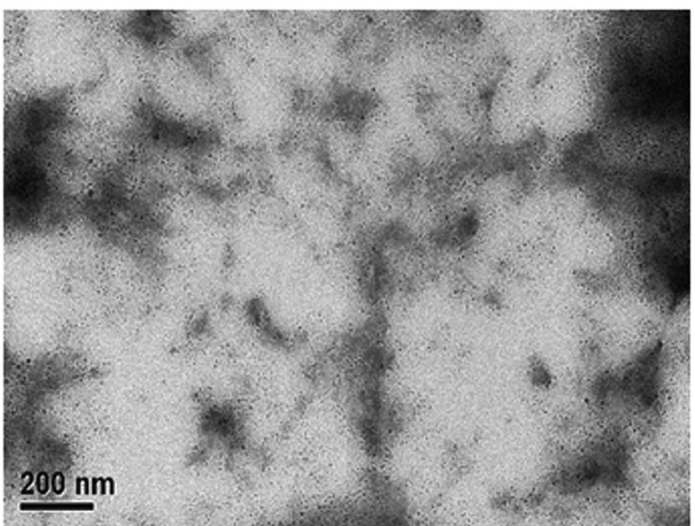

Fig. 8 TEM image of the PEGA13/PC ${ }_{71} B M(1: 2, w / w)$ blend film after annealing at $110^{\circ} \mathrm{C}$ for $10 \mathrm{~min}$.

photoactive layers of the PSCs. Fig. 5 displays the photocurrent density-voltage plots of the PSCs based on the PEGA13/ $\mathrm{PC}_{71} \mathrm{BM}$ blend film (PSC IV). Table 3 summarizes the PV properties of these PSCs. Because the optimal composition of the PEGA13/ $\mathrm{PC}_{61} \mathrm{BM}$ blend was $1: 2(\mathrm{w} / \mathrm{w})$, we studied the PSC IV based on a PEGA13/PC ${ }_{71} \mathrm{BM}$ blend also having a composition of $1: 2$ (w/w). The AFM images in Fig. 7 indicate that phase-separated interpenetrating networks with sizable domains were formed in the photoactive layer for the PEGA13/PC ${ }_{71} \mathrm{BM}$ blend film. In addition, we used TEM to further characterize the distribution of $\mathrm{PC}_{71} \mathrm{BM}$ in the $\mathrm{PT} / \mathrm{PC}_{71} \mathrm{BM}$ films. Fig. 8 presents the TEM image of the PEGA13/PC ${ }_{71} \mathrm{BM}$ blend film $(1: 2, \mathrm{w} / \mathrm{w})$. The dark areas in the image represent $\mathrm{PC}_{71} \mathrm{BM}$ domains, because the electron scattering density of $\mathrm{PC}_{71} \mathrm{BM}$ is greater than that of the conjugated polymer. The formation of phase-separated interpenetrating networks with sizable domains in the photoactive layer was confirmed. The hole mobility of the $1: 2(\mathrm{w} / \mathrm{w})$ PEGA13/ $\mathrm{PC}_{71} \mathrm{BM}$ blend film was approximately $3.17 \times 10^{-5}$ $\mathrm{cm}^{2} \mathrm{~V}^{-1} \mathrm{~s}^{-1}$ (Table 3). As displayed in Fig. 5, we observed much higher values of $J_{\mathrm{SC}}$ and PCE for the PSCs based on the PEGA13/ $\mathrm{PC}_{71} \mathrm{BM}$ blend films, as compared with those based on PT/ $\mathrm{PC}_{61} \mathrm{BM}$ blends, presumably because of the stronger and broader absorption of $\mathrm{PC}_{71} \mathrm{BM}$ in the visible region and the greater hole mobility of the PEGA13/PC 71 BM blend film. ${ }^{27}$ Apart from that, PV performance of the PEGA13/PC ${ }_{71} \mathrm{BM}$ based PSC was much better than that of the r-TPATh-PT/PC ${ }_{71} \mathrm{BM}$ based PSC. ${ }^{24}$ As compared to the r-TPATh-PT, the incorporation of the electron-deficient DG-TDPP units onto the polymer backbone resulted in a broader absorption band for PEGA13. Therefore, better PV performance was observed for the PEGA13 based PSC.

\section{Conclusion}

We have synthesized a series of PTs featuring di(ethylene glycol)-substituted 2,5-thienyl diketopyrrolopyrrole as conjugated units in the polymer backbones and $t$ TPA-containing moieties as pendant units. Incorporating the electrondeficient DG-TDPP moieties into the polymer backbone and appending the $t$ TPA units promoted charge balance and efficient conjugation within the extended conjugated frameworks of the polymers. The absorption ability and hole mobility of the PTs both improved upon optimization of the molar ratio of the $t$ TPA-based electron-donating pendant units and the electron-withdrawing DG-TDPP units in the polymer chains. The PV performance of the PEGA13-based PSCs was better than those of the PEGA12- and PEGA11-based PSCs.

\section{Acknowledgements}

We thank the Ministry of Science and Technology (MOST) of Taiwan for financial support.

\section{References}

1 M. Helgesen, R. Sondergaard and F. C. Krebs, J. Mater. Chem., 2010, 20, 36.

2 J. D. Chen, C. Cui, Y. Q. Li, L. Zhou, Q. D. Ou, C. Li, Y. F. Li and J. X. Tang, Adv. Mater., 2015, 27, 1035.

3 Y. W. Su, W. H. Lin, Y. J. Hsu and K. H. Wei, Small, 2014, 10, 4427.

4 Y. W. Su, S. C. Lan and K. H. Wei, Mater. Today, 2012, 15, 554.

5 M. H. Chen, J. Hou, Z. Hong, G. Yang, S. Sista, L. M. Chen and Y. Yang, Adv. Mater., 2009, 21, 4238.

6 B. Xu, Z. Zheng, K. Zhao and J. Hou, Adv. Mater., 2016, 28, 434.

7 W. Yue, R. S. Ashraf, C. B. Nielsen, E. C. Fregoso, M. R. Niazi, S. A. Yousaf, M. Kirkus, H. Y. Chen, A. Amassian, J. R. Durrant and I. McCulloch, Adv. Mater., 2015, 27, 4702.

8 J. Wang, M. Xiao, W. Chen, M. Qiu, Z. Du, W. Zhu, S. Wen, N. Wang and R. Yang, Macromolecules, 2014, 47, 7823.

9 L. Wang, S. Shi, D. Ma, S. Chen, C. Gao, M. Wang, K. Shi, Y. Li, X. Li and H. Wang, Macromolecules, 2015, 48, 287.

10 Y. R. Cheon, Y. J. Kim, J. J. Ha, M. J. Kim, C. E. Park and Y. H. Kim, Macromolecules, 2014, 47, 8570.

11 A. J. Heeger, Adv. Mater., 2014, 26, 10.

12 M. C. Scharber, D. Wuhlbacher, M. Koppe, P. Denk, C. Waldauf, A. J. Heeger and C. L. Brabec, Adv. Mater., 2006, 18, 789.

13 C. Cui, W. Y. Wong and Y. F. Li, Energy Environ. Sci., 2014, 7, 2276.

14 Y. Liang, Z. Xu, J. Xia, S. T. Tsai, Y. Wu, G. Li, C. Ray and L. Yu, Adv. Energy Mater., 2010, 22, E135.

15 F. Liu, Y. Gu, X. Shen, S. Ferdous, H. W. Wang and T. P. Russell, Prog. Polym. Sci., 2013, 38, 1990.

16 R. H. Lee and L. Y. Lee, Colloid Polym. Sci., 2011, 289, 1215. 17 G. Li, C. Kang, X. Gong, J. Zhang, C. Li, Y. Chen, H. Dong, W. Hu, F. Li and Z. Bo, Macromolecules, 2014, 47, 4645.

18 C. Duan, K. S. Chen, F. Huang, H. L. Yip, S. Liu, J. Zhang, A. K. Y. Jen and Y. Cao, Chem. Mater., 2010, 22, 6444.

19 Y. Li, H. Xia, B. Xu, S. Wen and W. Tian, J. Polym. Sci., Part A: Polym. Chem., 2008, 46, 3970.

20 Y. T. Chang, S. L. Hsu, M. H. Su and K. H. Wei, Adv. Mater., 2009, 21, 2093.

21 Z. G. Zhang, S. Y. Zhang, J. Min, C. H. Chui, J. Zhang, M. J. Zhang and Y. F. Li, Macromolecules, 2012, 45, 113. 
22 J. H. Tsai, W. Y. Lee, W. C. Chen, C. Y. Yu, G. W. Hwang and C. Ting, Chem. Mater., 2010, 22, 3290.

23 Z. Gu, P. Shen, S. W. Tsang, Y. Tao, B. Zhao, P. Tang, Y. Nie, Y. Fang and S. Tan, Chem. Commun., 2011, 47, 9381.

24 H. J. Wang, L. H. Chan, C. P. Chen, S. L. Lin, R. H. Lee and R. J. Jeng, Polymer, 2011, 52, 326.

25 N. Chakravarthi, K. Gunasekar, C. S. Kim, D. H. Kim, M. Song, Y. G. Park, J. Y. Lee, Y. Shin, I. N. Kang and S. H. Jin, Macromolecules, 2015, 48, 2454.

26 S. Mei, F. Wu, Y. Huang, B. Zhao and S. Tan, Eur. Polym. J., 2015, 67, 31.

27 H. J. Wang, J. Y. Tzeng, C. W. Chou, C. Y. Huang, R. H. Lee and R. J. Jeng, Polym. Chem., 2013, 4, 506.

28 S. Li, J. Yuan, P. Deng, W. Ma and Q. Zhang, Dyes Pigm., 2014, 106, 121.

29 D. F. Zeigler, K. A. Mazzio and C. K. Luscombe, Macromolecules, 2014, 47, 5019.

30 P. Zhou, D. Dang, J. Fan, W. Xiong, C. Yang, H. Tan, Y. Wang, Y. Liu and W. Zhu, Dyes Pigm., 2015, 112, 99.

31 Y. R. Liu, L. H. Chan and H. Y. Tang, J. Polym. Sci., Polym. Chem. Ed., 2015, 53, 2878.
32 K. Kranthiraja, K. Gunasekar, W. Cho, M. Song, Y. G. Park, J. Y. Lee, Y. Shin, I. N. Kang, A. Kim, H. Kim, B. Kim and S. H. Jin, Macromolecules, 2014, 47, 7060.

33 D. Dang, P. Zhou, Q. Peng, K. He, H. Jiang, P. Yang, H. Tan, Y. Wang, Y. Liu, G. Lei and W. Zhu, Dyes Pigm., 2014, 109, 6. 34 H. Liang, X. Zhang, R. Peng, X. Ouyang, Z. Liu, S. Chen and Z. Ge, Dyes Pigm., 2015, 112, 145.

35 G. Zhang, Y. Fu, Z. Xie and Q. Zhang, Sol. Energy Mater. Sol. Cells, 2011, 95, 1168.

36 S. Y. Shiau, C. H. Chang, W. J. Chen, H. J. Wang, R. J. Jeng and R. H. Lee, Dyes Pigm., 2015, 115, 35.

37 M. A. Naik, N. Venkatramaiah, C. Kanimozhi and S. Patil, J. Phys. Chem. C, 2012, 116, 26128.

38 R. H. Lee and L. W. Liu, Dyes Pigm., 2010, 84, 190.

39 O. Kwon, S. Barlow, S. A. Odom, L. Beverina, N. J. Thompson, E. Zojer, J. L. Brédas and S. R. Marder, J. Phys. Chem. A, 2005, 109, 9346.

40 C. Y. Huang, W. H. Lee and R. H. Lee, RSC Adv., 2014, 4, 48150. 